\title{
Stabilization of the Chemically Amplified Resist Process
}

\author{
Akira Oikawa, Yasunori Hatakenaka*, Yumiko Ikeda, Yoko Kokubo, \\ Shuichi Miyata, Nobuaki Santoh, and Naomichi Abe \\ Process Development Division, Fujitsu Limited, Kawasaki 211, Japan \\ *VLSI Laboratory, Fujitsu VLSI Limited, Kuwana-gun 511-01, Japan
}

We approached the problem of airborne chemical contamination from the processing side. By applying a very hydrophobic, polyolefinic coating resin, we completely eliminated T-tops. Patterning a resist in a low ammonia concentration also eliminated T-tops and resulted in low line width deviation rates against PED. When we patterned the resist with an ammonia concentration of $0.2 \mu \mathrm{g} / \mathrm{m}^{3}$, the deviation of the line width against PED was within the range 0.56 to $0.80 \mathrm{~nm} / \mathrm{min}$ for line-and-space patterns between 0.30 and $0.35 \mu \mathrm{m}$. These low deviation rates were considered to be acceptable for manufacturing purposes.

\section{Introduction}

Airborne chemical contamination is one of the biggest problems associated with chemically amplified positive resists. Basic contaminants exhaust photoacid generators at the resist surface, causing T-tops and delay-time instability.[1] The ideal solution is to stabilize resist materials since we would then need no additional processing costs. Much research has focused on trying to stabilize resist materials.[2-4] Resist stability has steadily improved. However, as long as we continue to use the chemical amplification approach, we can only cure the instability problem. To remove it completely, we need to approach the problem from the processing side.

Two approaches are possible. One is to protect resist surfaces by coating resins. The other is to reduce contaminant concentration by filtering. In this paper, we discuss both approaches. After a brief discussion of coating resins, we explain the effect of reducing the contaminant concentration.

\section{Experimental}

We used a typical chemically amplified positive resist in all patterning experiments. The base polymer of the resist is a copolymer of vinylphenol and tertiarybutylmethacrylate (Figure 1). The photoacid generator is triphenylsulfoniumtriflate. No additives besides surfactants were used in our resist. No special approach to the contaminant issue was used for this resist itself, but this suited our experiments since the results of approaching the issue could be obvious.

We coated Si wafers with the resist and then prebaked them at $110^{\circ} \mathrm{C}$ for 90 seconds. We then 


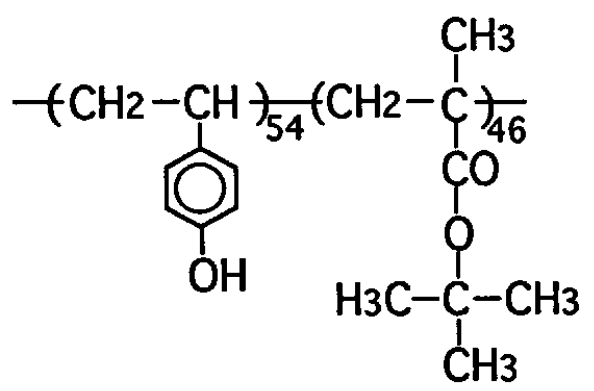

Figure 1. Molecular structure of the base polymer.

exposed the wafers $\left(\mathrm{NA}=0.45\right.$ ) and carried out a postexposure bake (PEB) at $90^{\circ} \mathrm{C}$ for 60 seconds. After cooling the wafers, we developed the resist using a tetramethyl ammonium hydroxide queous alkaline developer for 60 seconds.

Coating resins were applied just after prebaking the resist film and were stripped after the PEB if they were not soluble in the aqueous alkaline developer.

In the experiments to reduce the contaminant concentration, a $\mathrm{KrF}$ excimer stepper and a track system were physically integrated and equipped with chemical filter units. Wafers could thus be transported without exposure to the cleanroom atmosphere during all resist patterning processes except development.

In this study, we focused on ammonia concentration because no other organic bases were detected in our cleanroom. We used two techniques for measuring ammonia concentration. The first was a commonly used impinger method using ion chromatography. The other was a real-time ammonia monitoring system, which has a diffusion scrubber combined with the ion chromatographic system.

In Figure 2, we showed the pattern profile of the resist without coating resins or reducing ammonia concentration. We can find severe T-tops, showing that some approach from the processing side is innevitable.

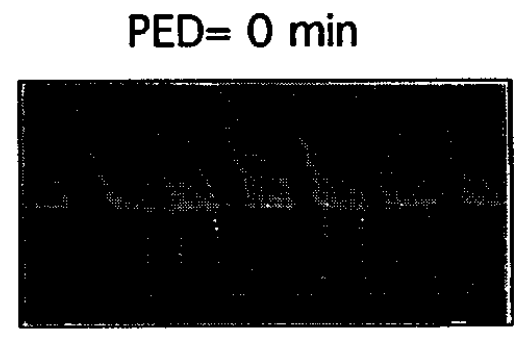

$0.30 \mu \mathrm{m} \mathrm{l} / \mathrm{s}$

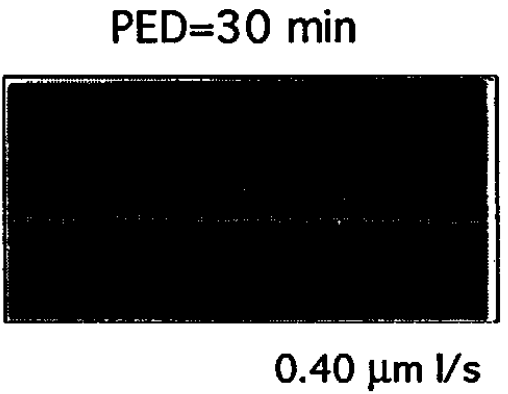

$0.40 \mu \mathrm{m} \mathrm{Vs}$

Figure 2. Resist patterns without coating resins or reduced ammonia concentration 


\section{Results and discussion}

\section{Coating resins}

Hydrophilic resins which are soluble in water have an advantage as a protective coating. They are stripped with the resist in alkaline development. However, we could not observe a sufficiently large enough effect as we showed in our previous paper.[5] Water in a resin could have affected the resist strongly. Some researches have reported that some hydrophilic resins were effective as protective resins.[6,7] If we had chosen the appropriate material and adopted the appropriate process condition, we could have found sufficient effect. We think, however, that this is too complicated to be realistic, since we have to check too many items. What we have to consider includes not only what kind of resins we should use, but also how to apply them on resists. The combination of resins and resists is also very important.

Conversely, we considered hydrohobic resins to be not only very effective, but also easy to handle, since they are hardly affected by water. We therefore developed the coating material based on a polyolefinic resin.[5] The polyolefinic resin is extremely hydrophobic; its contact angle with water is 94 degrees, and its water absorption is less than $0.01 \%$. Moisture absorption is also less than $0.01 \%$, and water permeability is less than $0.01 \mathrm{~g} / \mathrm{m}^{2} 24 \mathrm{~h}$. It was dissolved in a nonpolar solvent and a $0.20-\mu \mathrm{m}$-thick film was formed by spin-coating.

Figure 3 shows the effect of applying the polyolefinic resin. Without a resin coating, pattern profiles have fairly big T-tops. With the resin coating, however, the T-tops disappeared and a quarter-micron resolution was attained. This resin could also be applied to many other resists. Neither further optimization of the resin itself nor that of the process condition was needed. (a)

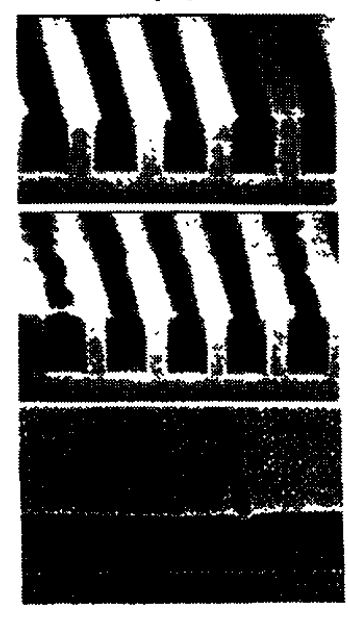

$0.40 \mu \mathrm{m} \mathrm{V} / \mathrm{s}$

$0.35 \mu \mathrm{m} \mathrm{V} / \mathrm{s}$

$0.30 \mu \mathrm{m} \mathrm{V} / \mathrm{s}$

$0.25 \mu \mathrm{m} \mathrm{l} / \mathrm{s}$

(b)
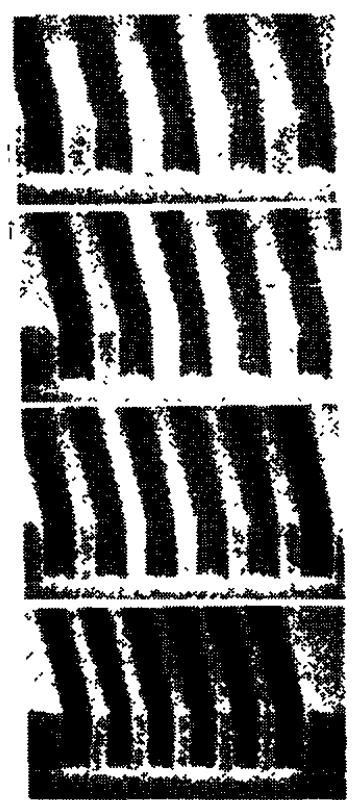

Figure 3. Resist patterns (a)with no coating, (b) with polyolefinic resin coating. 


\section{Effect of reducing contaminant concentration}

The polyolefinic coating resin was very effective and its usage was very simple. However, while using a coating resins, we cannot avoid a decrease in throughput and increase of material cost. We considered that contaminant control could best be addressed from the processing side. We studied the effect of reducing contaminant concentration.[8]

In Figure 4, we show a block diagram of the equipment with measuring points of ammonia concentration. We measured several times at each point, and each reading was less than $0.5 \mu \mathrm{g} / \mathrm{m}^{3}$ inside the equipment and was $2-15 \mu \mathrm{g} / \mathrm{m}^{3}$ outside it. The mean values obtained inside the equipment are shown in the figure. A very low ammonia concentration was attained everywhere inside the equipment.

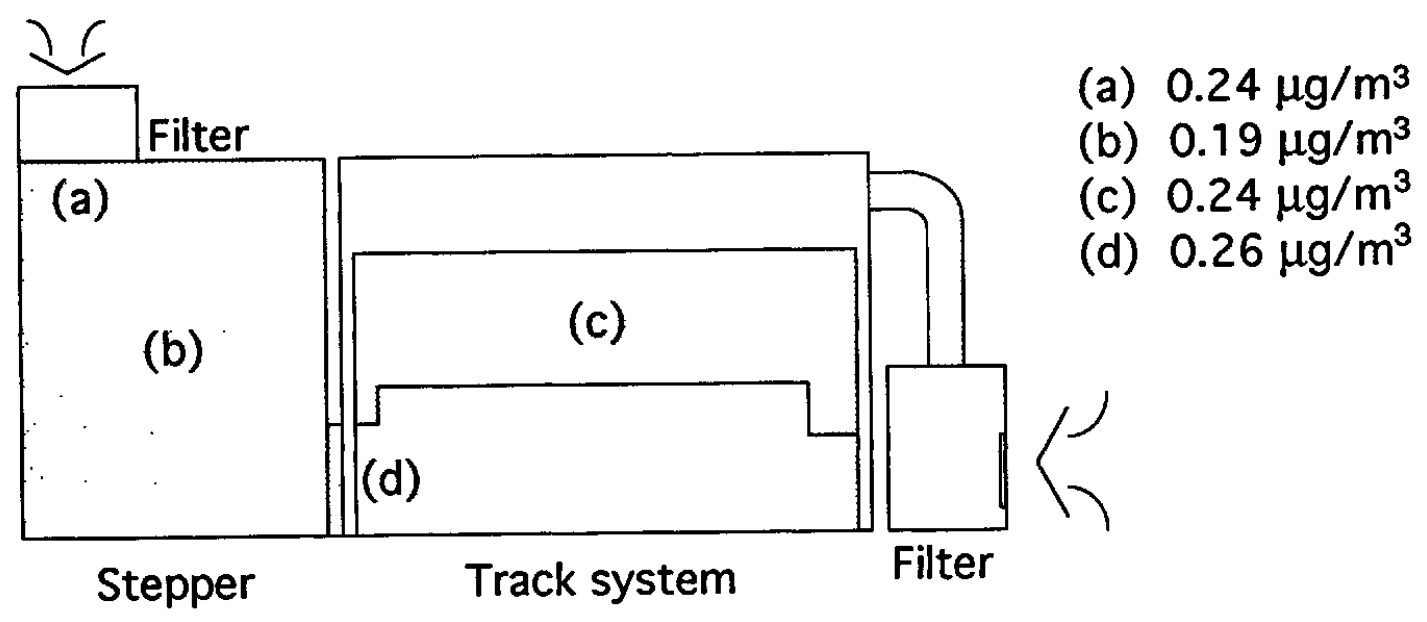

Figure 4. Experimental apparatus

(a)-(d) show the sampling points where ammonia concentration was measured.

(a) after filteration.

(b) above wafer stage.

(c) above wafer transfer unit near a PEB plate.

(d) interface unit.

We varied the postexposure delay (PED) from 0 up to 30 minutes when we patterned the resist. During PED, we left the wafers either inside the equipment or in a cleanroom atmosphere to check the effect of low ammonia concentration. Without reduced ammonia concentration, severe T-tops were found without PED, and no patterns were delineated after 30 minutes of PED. Figure 5 shows resist profiles in the low ammonia concentration. No T-tops were formed, even when PED was 30 minutes. The effect of reducing ammonia concentration was considerable. 


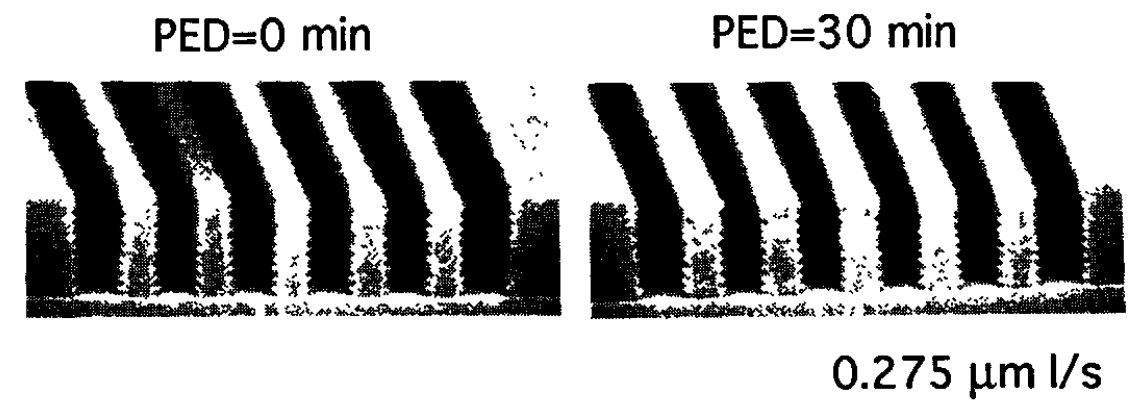

Figure 5. Resist profiles in the low ammonia concentration.

We measured the line widths of several line-and-space patterns with PED at 0,10 , and 30 minutes. In Figure 6, the line widths deviations were plotted against PED. When we left the wafers in the contaminated (high ammonia concentration) cleanroom during PED, we found a drastic increase in line width with PED time. By the time PED had reached 10 to 30 minutes, most data had disappeared off the graph. This meant the complete disappearance of resist patterns due to severe contamination. With low ammonia concentration, however, almost no deviation was observed.

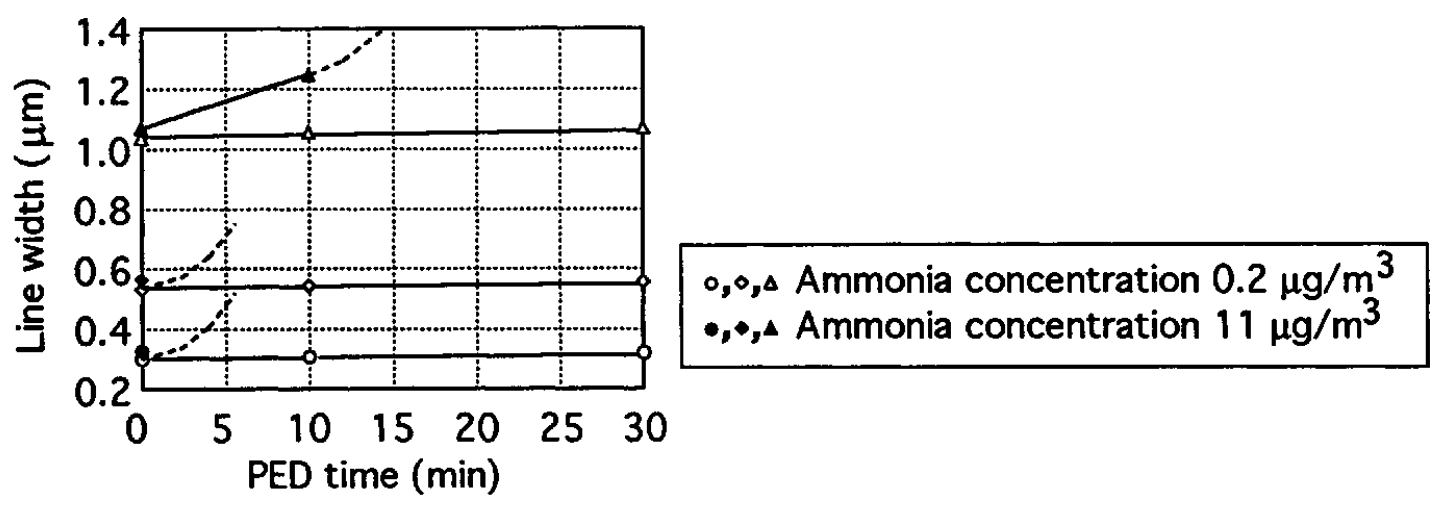

Figure 6. PED vs. line width.

The rate of line width increase outside the equipment was $18 \mathrm{~nm} / \mathrm{min}$. This was obtained using data from $1.0 \mu \mathrm{m}$ line-and-space patterns, because only $1 \mu \mathrm{m}$ patterns were delineated except at zero PED. The rates of line width deviations in the equipment were different for each pattern size. For 0.30 to $0.35 \mu \mathrm{m}$ line-and-space patterns, they ranged from 0.56 to $0.80 \mathrm{~nm} / \mathrm{min}$.

When a stepper and a track system are physically joined, PED hardly ever exceeds 10 minutes. If we permit a $10 \%$ deviation in the resist line width for manufacturing, the acceptable deviation rate would be less than $3 \mathrm{~nm} / \mathrm{min}$ for $0.3 \mu \mathrm{m}$ rules. Obviously, we could not use this resist without 
contamination control. However, if we could consistently maintain ammonia concentration inside the equipment as low as $0.2 \mu \mathrm{g} / \mathrm{m}^{3}$, the resist would be acceptable for manufacturing. This confirmed again that reducing ammonia concentration was very effective for process stabilization when using chemically amplified positive resists.

\section{Conclusion}

Applying the polyolefinic coating resin can eliminate $\mathrm{T}$-tops. Reducing ammonia concentration in the equipment was also very effective. Patterning resists showed no T-tops and gave low line width deviation rates against PED. Both methods are effective, but the latter is prefarable because it doesn't decrease the throughput and has almost no additional material costs. We conclude that reducing ammonia concentration in the patterning atmosphere by filtering was the most promising solution to the problem of airborne chemical contamination associated with chemically amplified positive resists.

\section{Acknowlegements}

We would like to thank Mr.Isamu Hanyu, Ms.Yuko Kaimoto, and Ms. Motoko Tanishima for their useful contributions.

\section{References}

1.S.A.MacDonald, N.J.Clecak, H.R.Wendt, C.G.Willson, C.D.Snyder, C.J.Knors, N.B.Deyoe, J.G.Maltabes, J.R.Morrow, A.E.McGuire and S.J.Holmes, Proc. SPIE, 1466, 1, 1991.

2.D.J.H.Funhoff, H.Binder, and R.Schwalm, Proc. SPIE, 1672, 46, 1992.

3.H.Ito, W.P.England, N.J.Clecak, G.Breyta, H.Lee, D.Y.Yoon, R.Sooriyakumaran, and W.D.Hinsberg, Proc. SPIE, 1925, 65, 1993.

4.K.J.Przybilla, Y.Kinoshita, T.Kudo, S.Masuda, H.Okazaki, M.Padmanaban, G.Pawlowski, H.Roeschert, W.Siess, and N.Suehiro, Proc. SPIE, 1925, 76, 1993.

5.A.Oikawa, N.Santoh, S.Miyata, Y.Hatakenaka, H.Tanaka and K.Nakagawa, Proc. SPIE, $1925,92,1993$.

6.O.Nalamasu, E.Reichmanis, M.Cheng, V.Pol, J.Kometani, F.Houlihan, T.Neenan, M.Bohrer,

D.Mixon, L.Thompson, C.Takemoto, Proc. SPIE, 1466, 13, 1991.

7.T.Kumada, Y.Tanaka, A.Ueyama, S.Kubota, H.Koezuka, T.Hanawa, H.Morimoto, Proc. SPIE, 1925, 31, 1993.

8.A.Oikawa, Y.Hatakenaka, Y.Ikeda, Y.Kokubo, M.Tanishima, N.Santoh, and H.Abe, Proc. SPIE, 1993, in press. 